\title{
The impact of exposure to wagering advertisements and inducements on intended and actual betting expenditure: An ecological momentary assessment study
}

\author{
MATTHEW BROWNE ${ }^{1 *}$, NERILEE HING ${ }^{1}$, ALEX M. T. RUSSELL ${ }^{1}$, ANNA THOMAS ${ }^{2}$ and REBECCA JENKINSON ${ }^{3,4}$ \\ ${ }^{1}$ School of Health, Medical and Applied Sciences, Central Queensland University, University Drive, QLD, Australia \\ ${ }^{2}$ Research Innovation and Entrepreneurship, RMIT University, Melbourne, VIC, Australia \\ ${ }^{3}$ Australian Gambling Research Centre, Australian Institute of Family Studies, Melbourne, VIC, Australia \\ ${ }^{4}$ School of Public Health and Preventive Medicine, Monash University, Melbourne, VIC, Australia
}

(Received: October 25, 2018; revised manuscript received: January 3, 2019; second revised manuscript received: February 1, 2019; accepted: February 24, 2019)

\begin{abstract}
Background and aims: Research suggests that a large proportion of regular sports and race bettors experience harm related to their gambling. In Australia, people who bet regularly are targeted by a proliferation of different forms of inducements and advertising - many of which are believed to encourage excessive betting and erroneous perceptions of risk. However, scant research has examined the impact of marketing messaging to this group, which is also limited to cross-sectional or qualitative designs. We aimed to determine whether exposure to wagering advertisements and inducements influenced intended betting expenditure, actual betting expenditure, and spending more than intended. Methods: We report on an ecological momentary assessment study, measuring regular exposure to 20 different forms of marketing, as well as wagering spend from 318 race bettors and 279 sports bettors. Up to 15 assessments per participant were conducted over 3 weeks $($ mean $=11.46$, median $=14)$, yielding 6,843 observations for analysis. Results: Exposure to advertising and inducements was reliably linked to a greater likelihood of betting, higher intended and actual betting expenditure, and spending more than intended. "Push" messaging and inducements that convey the impression of reduced risk (stake-back inducements and multibet offers) were particularly influential, as well as brands promoted during events and advertisements on betting websites/apps. Discussion and conclusions: Given that a large proportion of regular sports and race bettors experience problems, restrictions on these forms of marketing are advisable. These findings suggest that this is particularly important for marketing that is "pushed" to gamblers or that suggests reduced risk.
\end{abstract}

Keywords: marketing, advertising, inducements, betting, intentions, expenditure

\section{INTRODUCTION}

Wagering on racing and sporting events in Australia has grown substantially in recent years, where the legal age for gambling is 18 years or older. Race-betting losses totaled $\$ 3.3$ billion in 2016-2017, representing 14\% of all gambling expenditure; $\$ 1.1$ billion was lost on sports betting, representing $4.5 \%$ of gambling expenditure (Queensland Government, 2018). The promotion of sports and race betting reflects intense industry competition in this sector, and has been described as ubiquitous, relentless, and intrusive in Australia (Hing, Vitartas, \& Lamont, 2014; McMullan, 2011; Sproston, Hanley, Brook, Hing, \& Gainsbury, 2015) and elsewhere (Lopez-Gonzalez \& Griffiths, 2017a, 2017b). An understanding of the impact of this marketing on people who gamble particularly those at-risk of or experiencing problems - is therefore critically required.

Advertisements for wagering have predominated in commercial breaks during sports and racing broadcasts, promoting betting brands and products, as well as live betting odds and a wide range of inducements to bet (Gordon, Gurrieri, \& Chapman, 2015; Lopez-Gonzalez \& Griffiths, 2017a, 2017b; Milner, Hing, Vitartas, \& Lamont, 2013; Sproston et al., 2015). Sports entertainment shows are also punctuated by wagering industry commercials and contain sponsored segments and discussions of betting options and tips (Milner et al., 2013). Advertisements often target young adult males (Lopez-Gonzalez, Estévez, \& Griffiths, 2018a; LopezGonzalez, Guerrero-Solé, \& Griffiths, 2018; Sproston et al., 2015), and/or are designed to appeal to excitement, fun, luck, and value-for-money (Deans, Thomas, Daube, Derevensky, \& Gordon, 2016; Thomas, Lewis, McLeod, \& Haycock, 2012). Embedded advertising is also prolific, with wagering operator brands and logos often visible on sports player uniforms, banners, and within

* Corresponding author: Matthew Browne; School of Health, Medical and Applied Sciences, Central Queensland University, Bundaberg B8 G.47, University Drive, QLD 4670, Australia; Phone: +61 0438491 738; E-mail: m.browne@cqu.edu.au

This is an open-access article distributed under the terms of the Creative Commons Attribution-NonCommercial 4.0 International License, which permits unrestricted use, distribution, and reproduction in any medium for non-commercial purposes, provided the original author and source are credited, a link to the CC License is provided, and changes - if any - are indicated. 
stadiums (Hing, Vitartas, et al., 2014; Lopez-Gonzalez \& Griffiths, 2017a; Milner et al., 2013). It may also be found at race tracks, draped over horses, on staff uniforms, or installed at multiple track locations (Sproston et al., 2015). Digital media also enables direct advertising to individual customers, with a large volume of wagering messages typically received, via SMS, e-mail, phone, and social media, once individuals open a betting account (Hing, Gainsbury, et al., 2014; Russell, Hing, Browne, \& Rawat, 2018; Sproston et al., 2015).

Wagering inducements typically offer one or more incentives to bet, in addition to what is normally offered by the core wagering product. An audit in 2015 identified 15 generic types of wagering inducements offered among 30 major wagering brands accessible to Australian residents (Hing, Sproston, Brading, \& Brook, 2015). The most common offers included refund/stake-back offers, sign-up offers, providing a bonus or better odds, multibet offers, or winnings paid on losing bets. Wagering inducements aim to improve commercial outcomes, including recruiting, registering, and retaining customers (Weibe, 2008), as well as triggering additional sales, prompting brand switching, accelerating buying, intensifying purchasing, and encouraging riskier bets (Hing, Vitartas, \& Lamont, 2017; Newall, 2015).

Cross-sectional studies have revealed some associations between exposure to wagering advertising and intentions or behavior among people who gamble. Those with higher Problem Gambling Severity Index (PGSI) scores tended to have greater exposure to this type of advertising, to view it more favorably, be interested in the gambling sponsor's products, and be more willing to use them (Hing, Vitartas, \& Lamont, 2013). Another recent Australian study found that more frequent exposure to sports-embedded gambling advertising predicted greater intended frequency of sports betting, as did higher PGSI scores and previous sportsbetting participation (Hing, Lamont, Vitartas, \& Fink, 2015a). Problem gamblers (PGs; PGSI score: $8+$ ) indicated highest approval of, and feeling most encouragement to bet from, sports-betting promotions during televised sport, when compared to other gambler risk groups (Hing, Lamont, Vitartas, \& Fink, 2015b). Those with greater exposure to sports-betting advertising in digital media were more likely to bet regularly on sport, whereas those with greater exposure to race-betting advertising in traditional media were more likely to bet regularly on races (Sproston et al., 2015). A recent innovative study based on the Implicit Association Test found an implicit association between gambling and sport among youth aged 14-24 years, attributable to exposure to gambling advertising, sponsorship, and other brand encounters ( $\mathrm{Li}$, Browne, Langham, Thorne, \& Rockloff, 2018).

Little is known about how wagering inducements influence betting behavior, although recent research suggests they can lead to increased, more impulsive, and/or risky betting. A large survey of Australian sports bettors $(N=1,813)$ found that more frequent users of wagering inducements had a greater tendency to place impulse in-play bets, particularly PGs and frequent sports viewers (Hing, Russell, Li, \& Vitartas, 2018). Another quantitative study showed that wagering inducements tend to incentivize complex and risky bets (Newall, 2015). In an online experiment, Hing, Vitartas, et al. (2017) found that "risk free" bets that offer a refund under certain conditions were the most enticing form of inducement. Hing, Vitartas, et al. (2017) discuss the use of sign-up and refer-a-friend offers to not only entice new users, but also to encourage the creation of additional betting accounts, and the encouragement of volume purchasing through multibets. Cash-out inducements - those that refund or match part or all of a bet, under certain conditions - have also been criticized for facilitating loss of control due to the changed structural characteristics and the emotionally charged context in which cash-out decisions are typically made (Lopez-Gonzalez \& Griffiths, 2017a; Lopez-Gonzalez, Estévez, \& Griffiths, 2018 b). Others have argued that inducements tend to lower the perception of risk, stimulate impulsive bets, and promote feelings of control over betting outcomes (Deans, Thomas, Derevensky, \& Daube, 2017).

In summary, researchers have advanced numerous theoretical reasons why wagering advertisements and inducements might influence sports- and race-betting behavior, particularly for people at higher risk of experiencing gambling-related harm. However, research into the effects of wagering advertising and inducements is limited by its scarcity and by being cross-sectional or qualitative in nature. The present work attempts to partially address this gap through repeated sampling of regular wagerers' current behaviors and experiences over short time periods.

\section{Aims}

We aimed to determine whether exposure to wagering advertisements and inducements influenced intended betting expenditure, actual betting expenditure, and spending more than intended - and whether or not this is differed by PGSI group.

\section{METHODS}

We followed an ecological momentary assessment (EMA) design. EMA methodologies are particularly suited to assessing immediate influences on discrete, episodic behaviors, and have therefore been used in relation to cigarette smoking (Shiffman et al., 2002), binge eating (Haedt-Matt \& Keel, 2011), alcohol use (Hussong, Hicks, Levy, \& Curran, 2001; Litt, Cooney, \& Morse, 2000), and drug use (Freedman, Lester, McNamara, Milby, \& Schumacher, 2006; Hopper et al., 2006). After completing a baseline survey, participants completed up to 15 short EMA surveys: 5 per week for three non-consecutive weeks, with surveys on Monday, Wednesday, Friday, Saturday, and Sunday of survey weeks, because more sporting and racing contests occur on weekends in Australia. Survey invitations were sent at 5 p.m. on relevant days, with reminders the following morning. The surveys captured participants' exposure to different types of wagering advertisements and inducements as well as intended and actual betting behavior. The design aimed to maximize ecological validity and minimize recall bias because the surveys were conducted at, or very close to, the time and place that exposure to wagering marketing and betting occurred (Shiffman, Stone, \& Hufford, 2008). 


\section{Participants}

A total of 722 eligible respondents completed an initial online survey, which targeted two separate samples of Australian adults: regular horse/greyhound race bettors $(N=402)$ and regular sports bettors $(N=320)$. Of these, 597 (318 race and 279 sports) bettors completed at least one follow-up EMA survey and were available for analysis. Regular bettors were those who bet at least fortnightly on the targeted gambling activity. Eligible customers from a major sports-betting company operating in Australia, and respondents to a previous survey by the authors, were e-mailed an invitation to complete the survey (The betting company knew about, but had no control over, the nature and purpose of the research. We designed the sampling procedure and have no reason to think the betting company manipulated this, given the high proportions of respondents who met criteria for problem and at-risk gambling. The betting company had no further involvement in the study nor did they have any access to resultant data). The majority of respondents reported being Australian born, Englishspeaking male $(88.1 \%$ of race bettors and $92.5 \%$ of sports bettors), employed full-time, had post-secondary education, and lived as a couple with or without dependent children. Ages ranged between 18 and 84 years, with mean ages of $41.3(S D=13.7)$ years and $40.7(S D=14.1)$ years for race bettors and sports bettors, respectively.

The race bettor sample comprised 94 recreational gamblers (RG), 80 low-risk gamblers (LR), 93 moderate-risk gamblers (MR), and 51 PGs. The sports bettor sample comprised $70 \mathrm{RGs}, 82 \mathrm{LR}, 88 \mathrm{MR}$, and $39 \mathrm{PGs}$. Due to the modest sample size, and in the interest of model parsimony, PGSI scores were treated as a binary contrast: MR/PG status (PGSI 3+) versus not (PGSI 0-2). Thus, there were $144 / 318$ (45.2\%) $\mathrm{PG} / \mathrm{MR}$ race bettors and 127/279 (45.5\%) PG/MR sports bettors in the sample available for analysis. A high rate of problem gambling are observed in samples comprising regular sports and race gamblers, and higher rates are also observed in Internet panel samples.

\section{Measures}

Baseline survey. The survey captured demographic information and problem gambling risk status via the PGSI (Ferris \& Wynne, 2001).

EMA surveys. We used a list of wagering advertisements previously employed in a national Australian study of wagering advertising (Sproston et al., 2015) and the list of wagering inducements generated by an audit of these inducements (Hing et al., 2015). We added two further inducement types - cash out early on a multibet (a recently introduced inducement type) and rewards program offers (which had been out of scope in Hing et al.'s 2015 study). These are listed in Table 1 along with their abbreviations. Respondents indicated how often they had heard/seen each type of message (advertisement or inducement) listed in Table 1 in the past 24 or $48 \mathrm{hr}$ (since the last survey), rated on a scale ranging "never" (1), "a few times" (2), and "often" (3). The EMA surveys also asked respondents their actual and intended betting expenditure: "Roughly how much money did you place on race bets in the $24 \mathrm{hr}$ prior to 5 p.m. today?" and "Roughly how much money do you intend to place on race bets in the next $48 \mathrm{hr}$ after 5 p.m. today?"

Table 1. Race- and sports-betting advertisements and inducements measured and frequency in sample

\begin{tabular}{|c|c|}
\hline Description & Abbreviation \\
\hline \multicolumn{2}{|l|}{ Advertisements } \\
\hline $\begin{array}{l}\text { Betting brands promoted during live and televised (race/sports) events (e.g., logos and } \\
\text { signage) }\end{array}$ & Brands during events \\
\hline $\begin{array}{l}\text { Commentary promoting betting or betting odds during live and televised (racing/sports) } \\
\text { events }\end{array}$ & Commentary during events \\
\hline $\begin{array}{l}\text { Betting/odds related discussions in (race/sports) entertainment shows [e.g., (The Good } \\
\text { Oil/The Footy Show)] }\end{array}$ & Discussions in sports shows \\
\hline TV advertisements for betting brands & TV advertisements \\
\hline Radio or print advertisements for betting brands & Radio or print advertisements \\
\hline Advertisements on (race/sports) betting websites or apps (e.g., promoting particular bets) & Advertisements on betting websites/apps \\
\hline (Race/sports) betting advertisements on unrelated websites or apps & Advertisements on unrelated websites/apps \\
\hline Personal e-mails, text messages, or phone calls from (race/sports) betting companies & Direct messages \\
\hline Social media posts by (race/sports) betting companies (e.g., on Facebook, Twitter, etc.) & Social media posts \\
\hline \multicolumn{2}{|l|}{ Inducements } \\
\hline Sign-up bonus (to open a betting account) & Sign-up bonus \\
\hline Refer-a-friend offer & Refer-a-friend offer \\
\hline Click-to-call bonus (for using this technology to place in-play bet) & Click-to-call bonus \\
\hline Mobile-betting bonus (for betting via mobile phone or tablet) & Mobile-betting bonus \\
\hline Multibet offer (bonus bet, refund, or cash if multibet fails by one leg) & Multibet offer \\
\hline Stake-back offer (some money back if bet does not win) & Stake-back offer \\
\hline Match your stake or deposit (with bonus bets) & Match your stake/deposit \\
\hline Better odds or winnings for certain combined bets & Better odds or winnings \\
\hline Happy hours with better odds or winnings & Happy hours \\
\hline Cash out early on a multibet & Cash out early on multibet \\
\hline Rewards program run by betting companies & Rewards program \\
\hline
\end{tabular}




\section{Procedure}

Baseline survey. Dates for the 15 EMA surveys were provided in the information sheet of the baseline survey, allowing respondents to check their availability when consenting to participate. Surveys were completed online via computer or smartphone through the Qualtrics platform, and respondents were compensated for the baseline survey with a \$10 shopping voucher. Respondents who were aged 18 years and over bet at least fortnightly on horse/greyhound races or sports and were willing and able to participate in the EMA surveys were eligible for the subsequent phase.

All respondents were surveyed during 2017. The relevant dates for each week for all sports bettors were February 20-26, March 13-19, and April 3-9. For all race bettors, the dates were May 22-28, June 12-19, and July 3-9. Thus, there was a 2-week break between each survey week, and all respondents from each sample were surveyed simultaneously as others in the same sample.

$E M A$. Eligible race and sports bettor samples were invited to complete 15 EMA surveys across three time periods, being invited to five surveys per week on Monday, Wednesday, Friday, Saturday, and Sunday. The EMA survey dates were selected to coincide with racing and sporting event seasons, and the weekly surveys were conducted 3 weeks apart. Respondents were reimbursed a tiered amount based on the number of EMA surveys completed in the form of an electronic shopping voucher: \$30 for 4-8 surveys, $\$ 70$ for 9-12 surveys, and $\$ 100$ for $13-15$ surveys. The median (mean) number of surveys completed was 14 (11.6) for sports bettors, and 14 (11.3) for race bettors, yielding a total of 6,843 observations. To determine if there was any attrition bias in the samples, we examined the number of surveys completed by age and gender. A small relationship was found between number of surveys completed and age for race bettors only $(r=.16, p=.003)$; no effects were found for gender.

Statistical analysis. All analyses were undertaken in the open-source $\mathrm{R}$ statistical programming environment (R Core Team, 2013). For both sports and race bettors, three types of responses were analyzed:

Regression (1): intended spend (dollars)

Regression (2): actual spend (dollars)

Regression (3): actual spend controlling for intended spend.

By accounting for intentions, regression (3) aimed to estimate the influence of covariates on excessive spend, that is, spending more than intended. When treated as binary variables (i.e., spend/intention $>0$, discussed below), regression (3) captures effects on betting when one did not intend to do so. Spend intentions were lagged before analysis; they corresponded to intended spend in the following time period. A second contrast was included for control purposes for Saturdays versus other days, based on the assumption that higher levels of betting would occur during this period. Interaction terms were included with each promotion type to determine whether the influence of messaging varied by problem gambling status.

Repeated measures. We employed linear mixed effects (LMEs) models for each regression, implemented using the lme4 package (Bates, Mächler, Bolker, \& Walker, 2015) in order to account for the repeated measures. The LMEs included a random intercept for each participant in addition to the fixed effects, but no random slopes for participants.

Distribution of the response. Our response measures were actual and intended monetary spend in dollars. Both of these variables had a zero-inflated log-normal distribution, which is to be expected for this kind of measure. That is, they had a spike at zero reflecting time periods in which no money was (intended to be) spent, with non-zero spend amounts being heavily positively skewed. Log transformation and histograms of both variables confirmed that non-zero observations of both variables corresponded closely to a normal distribution. Hurdle regression models provide an orthodox and convenient means to handle this distribution. First, a binomial logistic model was fit to all available data, predicting the probability that spend was greater than zero. Second, a standard (linear link) regression was fit to the log-transformed positive responses only. Thus, the two components of the model capture, respectively, (a) the likelihood of betting (or intention to bet), and (b) the amount spent (or intended to spend), given that betting took place.

Selection and aggregation of inducements and advertisements. We measured exposure to 20 specific types of messaging, which displayed an average correlation of .36 (sports) and .37 (race). Simultaneous entry of all predictors was not feasible due to deleterious effects on model degrees of freedom, multicollinearity, and numerical stability. Our first approach was to aggregate exposure to inducement and advertisement types by a simple sum of all the coded responses $(0,1,2)$ of exposure to specific types of messaging.

To investigate the impact of specific messaging, we employed a modern computational method of variable selection called the "lasso," using the glmnet package (Friedman, Hastie, \& Tibshirani, 2008, 2010). The lasso can be understood as a form of robust variable selection, which is not vulnerable to the well-known instability of classical stepwise regression. In brief, a regularization term, which penalizes non-zero beta coefficients, is added to the normal regression penalty for prediction errors. By varying the weight of this term and testing via cross-validation, the conflicting goals of model parsimony/sparsity and fit to data can be balanced.

For each of the regressions on specific inducements and advertisements, we first ran the lasso procedure, which yielded an ordering of these inducements and advertisements, from most to least salient. This determined the order of variable inclusion in the hurdle LME models. We stopped including further predictors when it did not yield a significant improvement in model fit. Only the final models are reported. Interactions between messaging and problem gambling status were also considered to test for differential influence on those with gambling problems.

\section{Ethics}

The study procedures were carried out in accordance with the Declaration of Helsinki. The institutional ethics committee of Central Queensland University approved the study (H16/06-178). All subjects were informed about the purpose of the research and all provided informed consent. 


\section{RESULTS}

Table 2 summarizes the prevalence of exposure to specific messaging types reported by race and sports bettors during the EMA survey. Table 3 summarizes the frequency and quantity of reported spend. The LME regression summaries are organized below with respect to sample (race bettors and sports bettors), representation of the messaging variables (aggregated and lasso-selected), type of analysis (intended, actual, and excessive spend), and hurdle component (logistic and log-normal).

\section{Race betting}

Table 4 summarizes models estimating the impact of aggregate advertisements and inducements on race bettors. Participants were more likely to bet, and also spend more on Saturdays. Intentions were strongly positively predictive of actual expenditure. Exposure to advertising and inducements did not affect expressed intentions, but both were associated with greater likelihood of betting, and a greater spend when betting. Only advertisements predicted (excess) spend when controlling for intentions. PG/MR status was consistently associated with greater intended, actual, and excessive spending. Interestingly, although PG/MR gamblers did not gamble more often than others, they were more likely to gamble in time periods in which they had not intended to do so. No significant interactions between PG/MR status and aggregate messaging exposure were found.

Table 5 summarizes models estimating the impact of specific advertisements and inducements on race bettors. An
Table 3. Summary of spending reported by race and sports bettors during the EMA

\begin{tabular}{lcc}
\hline & $\begin{array}{c}\text { Race bettors } \\
\text { (N. obs. }=3,592)\end{array}$ & $\begin{array}{c}\text { Sports bettors } \\
\text { (N. obs. }=3,231)\end{array}$ \\
\hline $\begin{array}{l}\text { Mean } \\
\text { Obs. with non-zero spend }\end{array}$ & $71.46 \%$ & $69.60 \%$ \\
$\begin{array}{l}\text { Quartiles of non-zero obs. } \\
\text { Lower quartile 25\% }\end{array}$ & $\$ 25.00$ & \\
Median 50\% & $\$ 80.00$ & $\$ 20.00$ \\
Upper quartile 75\% & $\$ 292.50$ & $\$ 50.00$ \\
\hline
\end{tabular}

Note. EMA: ecological momentary assessment.

interaction model with $\mathrm{PG} / \mathrm{MR}$ was also run but is not reported because it did not yield a significant improvement in fit. Exposure to advertising brands, websites, and in-game commentary was each independently associated with a greater likelihood of betting. Only brands and commentary were associated with increased spend, and these were also linked to excess spending. Inducements offered via direct messaging increased the likelihood of intending to bet, actual betting, and betting when not intending to do so. Stake-back offers increased the likelihood of betting and the amount spent.

\section{Sports betting}

Table 6 summarizes models estimating the impact of aggregate advertisements and inducements on sports bettors. Similar to race bettors, participants were more likely to bet and to spend more on Saturdays. They were more likely to

Table 2. Prevalence of exposure to advertisements and inducements for race and sports bettors in the EMA data set

\begin{tabular}{|c|c|c|c|c|c|c|}
\hline & \multicolumn{3}{|c|}{ Race bettors (N. obs. $=3,592)$} & \multicolumn{3}{|c|}{ Sports bettors (N. obs. $=3,231)$} \\
\hline & Never $(\%)$ & Few $(\%)$ & Often $(\%)$ & Never $(\%)$ & Few $(\%)$ & Often $(\%)$ \\
\hline \multicolumn{7}{|l|}{ Advertisements } \\
\hline Brands during events & 37.33 & 43.88 & 18.79 & 33.61 & 45.93 & 20.46 \\
\hline Commentary during events & 47.66 & 37.67 & 14.67 & 49.80 & 37.64 & 12.57 \\
\hline Discussions in sports shows & 65.06 & 26.20 & 8.74 & 57.47 & 31.94 & 10.58 \\
\hline TV advertisements & 32.24 & 49.11 & 18.65 & 31.14 & 46.49 & 22.38 \\
\hline Radio or print advertisements & 47.94 & 40.67 & 11.39 & 54.75 & 34.73 & 10.52 \\
\hline Advertisements on betting websites/apps & 41.56 & 43.51 & 14.92 & 39.83 & 45.50 & 14.67 \\
\hline Advertisements on unrelated websites/apps & 58.44 & 33.05 & 8.52 & 57.04 & 34.66 & 8.29 \\
\hline Direct messages & 41.87 & 46.99 & 11.14 & 44.63 & 45.19 & 10.18 \\
\hline Social media posts & 56.96 & 31.93 & 11.11 & 55.00 & 32.68 & 12.32 \\
\hline \multicolumn{7}{|l|}{ Inducements } \\
\hline Sign-up bonus & 54.37 & 37.17 & 8.46 & 59.80 & 33.61 & 6.59 \\
\hline Refer-a-friend offer & 80.68 & 16.90 & 2.42 & 81.00 & 15.94 & 3.06 \\
\hline Click-to-call bonus & 84.38 & 13.06 & 2.56 & 84.52 & 11.79 & 3.68 \\
\hline Mobile-betting bonus & 74.47 & 20.46 & 5.07 & 77.28 & 17.92 & 4.80 \\
\hline Multibet offer & 46.88 & 40.76 & 12.36 & 40.27 & 44.41 & 15.32 \\
\hline Stake-back offer & 41.82 & 42.68 & 15.51 & 43.42 & 41.01 & 15.57 \\
\hline Match your stake/deposit & 48.69 & 40.31 & 11.00 & 53.95 & 34.91 & 11.14 \\
\hline Better odds or winnings & 64.06 & 28.59 & 7.35 & 65.52 & 27.86 & 6.62 \\
\hline Happy hours & 87.17 & 10.80 & 2.03 & 87.77 & 9.04 & 3.19 \\
\hline Cash out early on multibet & 53.42 & 36.69 & 9.88 & 54.69 & 34.60 & 10.71 \\
\hline Rewards program & 54.93 & 35.58 & 9.49 & 59.05 & 31.60 & 9.35 \\
\hline
\end{tabular}

Note. EMA: ecological momentary assessment. 
Impact of advertisements and inducements on betting

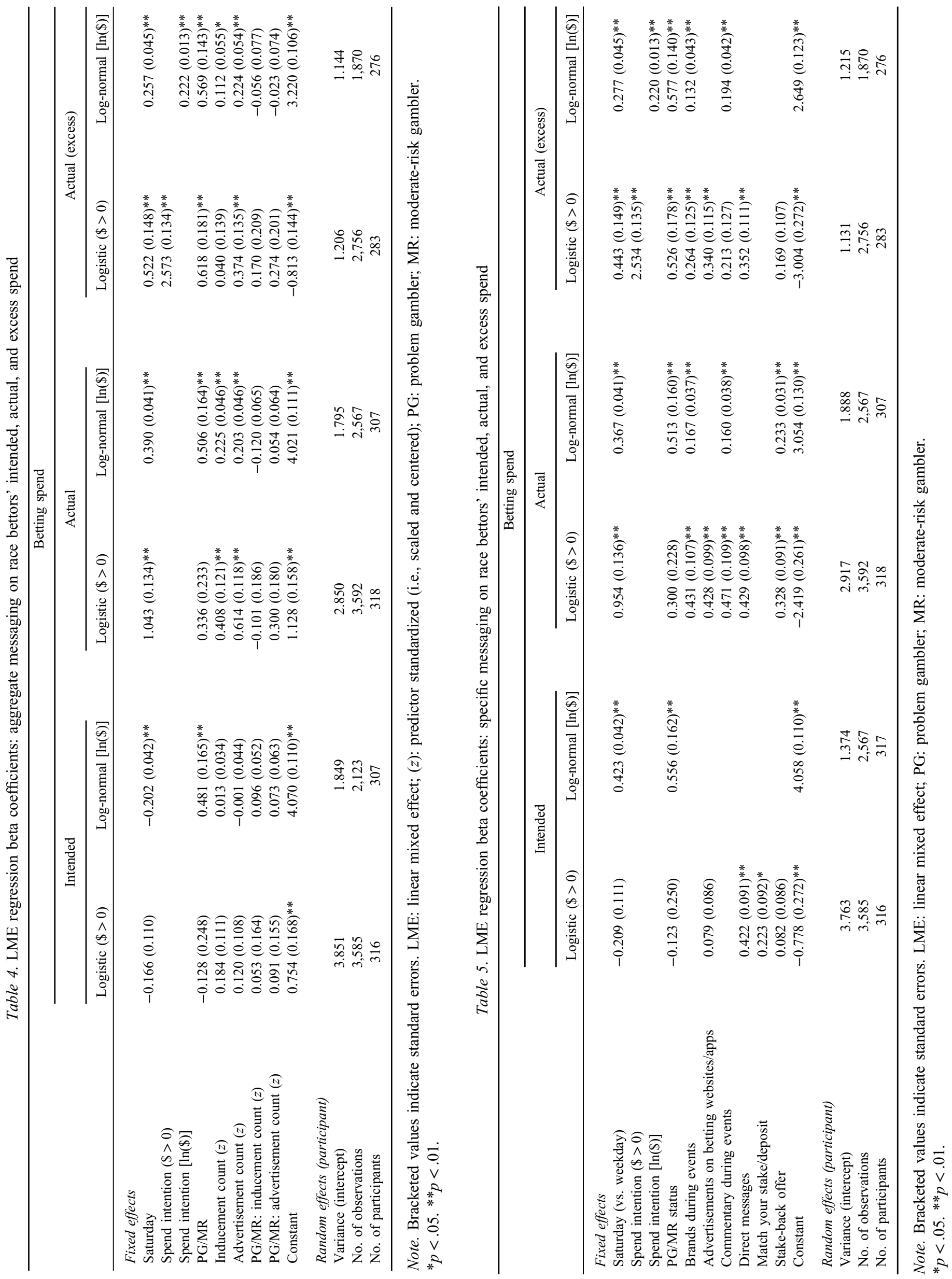




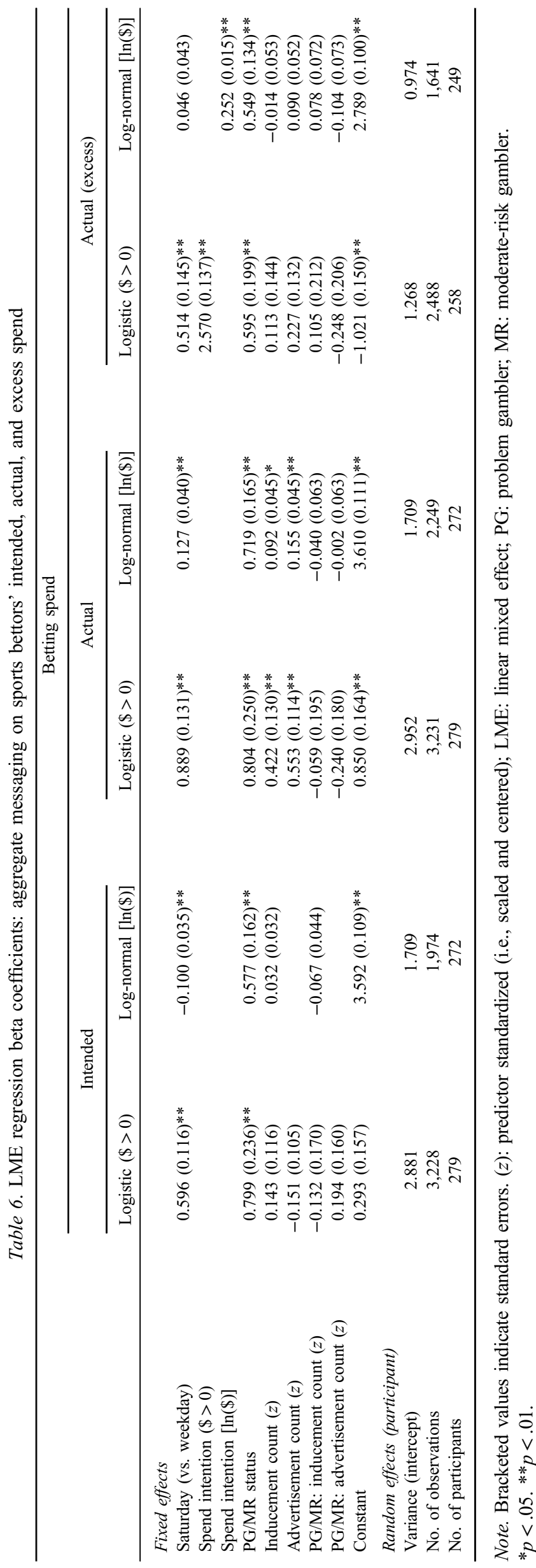

bet on Saturdays, and when they had not originally intended to so, but did not spend more than intended on Saturdays. PG/MR sports gamblers bet more often, spent more when betting, were more likely to bet when not intending to do so, and tended to spend more than intended. However, there was no differential impact of messaging on PG/MR gamblers compared to others. Both aggregate advertisements and inducements were associated with a greater likelihood of betting, and advertisements were related to greater spend. However, neither was associated with spend in excess of intentions.

Table 7 summarizes models estimating the impact of specific advertisements and inducements on sports bettors. An interaction model with $\mathrm{PG} / \mathrm{MR}$ yielded an improvement in fit due to $\mathrm{PG} / \mathrm{MR}$ gamblers being more likely to gamble throughout the week. As there was no significant differential influence of messaging on PG/MR gamblers, the main effects model are reported. Exposure to advertising on websites/apps and brands, as well as to multibet offer inducements was associated with a higher likelihood of betting. Exposure to television advertisements was related to a greater spend. Exposure to gambling websites/apps predicted an increased likelihood of betting when not originally intended.

Hurdle regression models with log-transformation of the response make it difficult to interpret coefficients in terms of the raw differences in dollars spent, and LME models are not amenable to straight-forward estimation of effect size. However, summarizing raw differences is problematic because of the disproportionate influence of a small number of huge spend amounts. Accordingly, Table 8 summarizes the simple average of spend with respect to differing exposure to inducements and advertisements, excluding spends of $\$ 500$ or greater. A consistent increase in average spend is apparent as exposure increases, for both advertisements and inducements, and for both sports and race bettors.

\section{DISCUSSION}

We found that aggregate exposure to wagering inducements and advertisements was associated with a greater likelihood of betting and increased spend when betting. For race bettors, but not sports bettors, aggregate advertising was also related to betting when not intended and spending more than intended. Given these effects, it is interesting to note messaging in general did not affect betting intentions, with the exception of direct messaging - according to the findings of a recent similar study (Russell et al., 2018). In general, exposure to advertisements had a stronger relationship with betting compared to inducements. These results suggest that a reduction in wagering advertising would be a positive consumer protection measure across the board, as it would be likely to reduce betting expenditure and spending more than intended, including among people at higher risk of experiencing gambling-related harm. In March 2018, gambling advertising was banned from live sports broadcasts on television and radio in Australia between 5:00 a.m. and 8:30 p.m. in order to reduce exposure of children to sportsrelated gambling. This ban followed several years of strong community concern (Australian Communication and Media Authority [ACMA], 2013). If this ban was extended to 
encompass a blanket ban on wagering advertising, or at the very least to cover the entirety of sports games and racing programs, it may also assist in reducing harmful gambling behaviors among adults. The consistent level of community anger toward wagering advertising suggests that strengthening advertising restrictions would be supported at the community level (ACMA, 2013). To best protect consumers, any such restrictions should encompass digital as well as traditional advertising, to prevent migration of advertising to less restricted online, social media, and mobile platforms, as has occurred with the introduction of previous advertising restrictions (Gainsbury et al., 2015; Sproston et al., 2015).

No differential effects of messaging on the $\mathrm{PG} / \mathrm{MR}$ gamblers were found. Compared to other regular bettors, PG/MR gamblers did not bet more often; rather, they tended to spend more on betting on days when they bet, bet when not originally intending to, and spend more than intended. Nevertheless, research suggests that $41 \%$ of all regular (at least monthly) sports bettors and race bettors in Australia experience one or more gambling-related problems (Armstrong \& Carroll, 2017a, 2017b). Furthermore, this study found that exposure to wagering marketing increased the likelihood of betting and spending when betting. Therefore, it can be concluded that wagering marketing negatively affects substantial numbers of bettors already at-risk of, or currently experiencing gambling problems. Young adult males are the target group for this marketing, a group who are increasingly reporting betting-related problems and harm (Hing, Russell, Vitartas, \& Lamont, 2016).

Inducements implicated as having most influence on betting expenditure were multibet and stake-back offers, which refund part or all of the bets (under certain conditions) via cash, bonus bets, deposits, or reward points. The appeal of these forms of messaging is based on conveying the impression of reduced risk, but they actually increase losses by encouraging increased betting expenditure. Conveying the impression of reduced risk is likely to contribute to erroneous cognitions (Hing, Sproston, Brook, \& Brading, 2017; Lopez-Gonzalez \& Griffiths, 2017b). A targeted approach to consumer protection would be, therefore, to ban or otherwise restrict these types of inducements.

A problematic form of wagering advertising is direct messaging via e-mails, texts, and phone calls from wagering operators. The majority of these direct messages promotes specific wagering inducements, and bettors report that this marketing is intense and particularly influential on their betting, encouraging them to bet and to spend more on betting (Russell et al., 2018). This study similarly found that this type of advertising was associated with a greater intention to bet, more betting, and betting more than intended for regular race bettors. A prudent regulatory measure would be to ban this type of push advertising or to mandate a rigorous opt-in requirement to receive these targeted inducements, rather than the current opt-out system.

\section{Limitations}

Only at-least fortnightly sports bettors and race bettors were included, which preclude any assessment of the effects of wagering advertisements and inducements on less frequent bettors. Substantial attrition occurred before and during the 
Table 8. Average spend of sports and race bettors with respect to exposure to inducements and advertisements

\begin{tabular}{lccccc}
\hline & \multicolumn{2}{c}{ Sports bettors } & & \multicolumn{2}{c}{ Race bettors } \\
\cline { 2 - 3 } \cline { 5 - 6 } Exposure & \multicolumn{2}{c}{ N. obs. $=2,897^{*}$} & & \multicolumn{2}{c}{ N. obs. $=3,144^{*}$} \\
\cline { 2 - 3 } \cline { 5 - 6 } & Inducements & Advertisements & & Inducements & Advertisements \\
\hline None & $\$ 33.40$ & $\$ 42.04$ & & $\$ 33.71$ & $\$ 42.44$ \\
$1-4$ & $\$ 53.78$ & $\$ 53.78$ & & $\$ 68.90$ & $\$ 62.61$ \\
$5+$ & $\$ 67.35$ & $\$ 65.67$ & & $\$ 78.09$ & $\$ 82.67$ \\
\hline
\end{tabular}

Note. *One-sided trimmed mean: cases reporting spend exceeding $\$ 500(\sim 8 \%)$ excluded from calculation. Zero spend observations included.

EMA survey periods. Thus, those who opted into the study, and who completed most or all EMA surveys may differ from the population of regular sports and race bettors, although no attrition bias was found by age or gender. The EMA intervals varied between $24 / 48 \mathrm{hr}$ to conform to a weekly schedule. Our "Saturday" contrast only partially accounted for this. In order to maximize survey brevity, we only asked about how much money was placed (or intended to be placed) on betting and did not ask about wins. While we attempted to describe each type of advertisement and inducement as accurately as possible, some participants may have confused some types, for example, "Betting brands promoted during live and televised (race/sports) events (e.g., logos and signage)" with "TV advertisements for betting brands." Accurately measuring exposure to each type of wagering advertisements and inducements was impossible for numerous types of marketing, for example, number of brand exposures or amount of commentary during televised events. Finally, the EMA design does not conclusively demonstrate that exposure to messaging causes betting behavior: betting on or watching sports is likely to increase exposure to some (but not all) forms of messaging. Future work might strengthen a causal interpretation by attempting to measure exposure occurring strictly before the betting behavior. Nevertheless, by observing exposure, intentions, and betting behavior close to the time at which it occurred, the EMA design provides stronger evidence of the link between advertisement and inducement exposure and subsequent betting expenditure.

\section{CONCLUSIONS}

Advertising and inducements are reliably linked to more intense betting behavior, particularly "push" messaging and inducements that convey the impression of reduced risk. Given that a large proportion of regular sports and race bettors experience gambling-related harm, and are known to be vulnerable to such messaging, restrictions on these forms of marketing would be a positive consumer protection measure that is likely to be welcomed by the wider community.

Funding sources: This study was funded by the Victorian Responsible Gambling Foundation.

Authors' contribution: MB conducted the statistical analyses and led the drafting of the manuscript. NH helped to design the study and the study instruments, wrote the foundation literature review and discussion, and critically reviewed the manuscript. AMTR helped to design the study and survey instruments, assisted with data preparation and initial analyses, and critically reviewed the manuscript. AT and RJ helped to design the study and the study instruments and critically reviewed the manuscript.

Conflict of interest: MB has received funding from the New South Wales Office or Liquor and Gaming, the Victorian Responsible Gambling Foundation, the Queensland Government Department of Health, the Tasmanian Department of Treasury and Finance, the Alberta Gambling Research Institute, Gambling Research Australia, the New Zealand Ministry of Health, the Department of Families, Housing, Community Services and Indigenous Affairs, the Australian Department of Innovation, Industry, Science and Research, and the Department of Foreign Affairs and Trade. He declares that he has no conflict of interest in relation to this research. NH has received research grants from the Australian Research Council, Gambling Research Australia, the Queensland Government, NSW Government, South Australian Government, Victorian Government, Victorian Responsible Gambling Foundation, the Australian Communications and Media Authority, the Alberta Gambling Research Institute, and the Australian National Research Organisation for Women's Safety. She has conducted unpublished consultancy work for Echo Entertainment, Singapore Pools, and Sportsbet aimed at improving their responsible gambling practices. She declares no conflict of interest in relation to this manuscript. AMTR has received research grants from Gambling Research Australia, the Victorian Responsible Gambling Foundation, the Queensland and New South Wales Governments, the Alberta Gambling Research Institute, and the National Association of Gambling Studies. He has conducted unpublished consultancy work for Echo/Star Entertainment, aimed at improving their responsible gambling practices in relation to gambling by their employees. He declares no conflict of interest in relation to this manuscript. He has also received research grants from Gambling Research Australia, Victorian Responsible Gambling Foundation, the Victorian Government and the Australian Government. He has been paid to conduct peer reviews for Gambling Research Australia and the Victorian Responsible Gambling Foundation. RJ has received research grants from the Victorian Responsible Gambling Foundation, the Victorian Government, the Australian Government Department of Health, the Australian Government Department of Social 
Services, the National Health and Medical Research Council, the National Drug Law Enforcement Fund, Australia's National Research Organisation for Women's Safety, and the Invergowrie Foundation. She works at the Australian Gambling Research Centre which is funded by the Australian Government. She declares no conflict of interest in relation to this manuscript.

\section{REFERENCES}

Australian Communication and Media Authority [ACMA]. (2013). Betting odds and advertising for betting agencies during sports broadcasts: Community research. Canberra, Australia: ACMA.

Armstrong, A., \& Carroll, M. (2017a). Sports betting in Australia. Melbourne, Australia: Australian Gambling Research Centre. Retrieved from https://aifs.gov.au/agrc/publications/sportsbetting-australia

Armstrong, A., \& Carroll, M. (2017b). Race betting in Australia. Melbourne, Australia: Australian Gambling Research Centre. Retrieved from https://aifs.gov.au/agrc/publications/race-bettingaustralia

Bates, D., Mächler, M., Bolker, B., \& Walker, S. (2015). Fitting linear mixed-effects models using lme4. Journal of Statistical Software, 67(1), 1-48. doi:10.18637/jss.v067.i01

Deans, E. G., Thomas, S. L., Daube, M., Derevensky, J., \& Gordon, R. (2016). Creating symbolic cultures of consumption: An analysis of the content of sports wagering advertisements in Australia. BMC Public Health, 16(1), 208. doi:10. 1186/s12889-016-2849-8

Deans, E. G., Thomas, S. L., Derevensky, J., \& Daube, M. (2017). The influence of marketing on the sports betting attitudes and consumption behaviours of young men: Implications for harm reduction and prevention strategies. Harm Reduction Journal, 14(5), 1-12. doi:10.1186/s12954-017-0131-8

Ferris, J., \& Wynne, H. (2001). The Canadian Problem Gambling Index. Ottawa, ON: Canadian Centre on Substance Abuse.

Freedman, M. J., Lester, K. M., McNamara, C., Milby, J. B., \& Schumacher, J. E. (2006). Cell phones for ecological momentary assessment with cocaine-addicted homeless patients in treatment. Journal of Substance Abuse Treatment, 30(2), 105-111. doi:10.1016/j.jsat.2005.10.005

Friedman, J., Hastie, T., \& Tibshirani, R. (2008). Sparse inverse covariance estimation with the graphical lasso. Biostatistics, 9(3), 432-441. doi:10.1093/biostatistics/kxm045

Friedman, J., Hastie, T., \& Tibshirani, R. (2010). Regularization paths for generalized linear models via coordinate descent. Journal of Statistical Software, 33(1), 1-22. doi:10.18637/jss. v033.i01

Gainsbury, S. M., King, D., Delfabbro, P., Hing, N., Russell, A., Blaszczynski, A., \& Derevensky, J. (2015). The use of social media in gambling. Melbourne, Australia: Gambling Research Australia.

Gordon, R., Gurrieri, L., \& Chapman, M. (2015). Broadening an understanding of problem gambling: The lifestyle consumption community of sports betting. Journal of Business Research, 68(10), 2164-2172. doi:10.1016/j.jbusres.2015.03.016

Haedt-Matt, A. A., \& Keel, P. K. (2011). Revisiting the affect regulation model of binge eating: A meta-analysis of studies using ecological momentary assessment. Psychological Bulletin, 137(4), 660-681. doi:10.1037/a0023660

Hing, N., Gainsbury, S., Blaszczynski, A., Wood, R., Lubman, D., \& Russell, A. (2014). Interactive gambling. Melbourne, Australia: Gambling Research Australia. Retrieved from http:// www.gamblingresearch.org.au/resources/6482d5fa-f068-41e5921f-facd4f10365e/interactive+gambling.pdf

Hing, N., Lamont, M., Vitartas, P., \& Fink, E. (2015a). How sports bettors respond to sports-embedded gambling promotions: Implications for compulsive consumption. Journal of Business Research, 68(10), 2057-2066. doi:10.1016/j.jbusres.2015.03.003

Hing, N., Lamont, M., Vitartas, P., \& Fink, E. (2015b). Sportsembedded gambling promotions: A study of exposure, sports betting intention and problem gambling amongst adults. International Journal of Mental Health and Addiction, 13(1), 115-135. doi:10.1007/s11469-014-9519-9

Hing, N., Russell, A. M. T., Li, E., \& Vitartas, P. (2018). Does the uptake of wagering inducements predict impulse betting on sport? Journal of Behavioral Addictions, 7(1), 146-157. doi:10.1556/2006.7.2018.17

Hing, N., Russell, A. M. T., Vitartas, P., \& Lamont, M. (2016). Demographic, behavioural and normative risk factors for gambling problems amongst sports bettors. Journal of Gambling Studies, 32(2), 625-641. doi:10.1007/s10899-015-9571-9

Hing, N., Sproston, K., Brading, R., \& Brook, K. (2015). Review and analysis of sports and race betting inducements. Melbourne, Australia: Victorian Responsible Gambling Foundation.

Hing, N., Sproston, K., Brook, K., \& Brading, R. (2017). The structural features of sports and race betting inducements: Issues for harm minimisation and consumer protection. Journal of Gambling Studies, 33(2), 685-704. doi:10.1007/s10899016-9642-6

Hing, N., Vitartas, P., \& Lamont, M. (2013). Gambling sponsorship of sport: An exploratory study of links with gambling attitudes and intentions. International Gambling Studies, 13(3), 281-301. doi:10.1080/14459795.2013.812132

Hing, N., Vitartas, P., \& Lamont, M. (2014). Promotion of gambling and live betting odds during televised sport: Influences on gambling participation and problem gambling. Brisbane, Australia: Report prepared for the Queensland Department of Justice and Attorney-General.

Hing, N., Vitartas, P., \& Lamont, M. (2017). Understanding persuasive attributes of sports betting advertisements: A conjoint analysis of selected elements. Journal of Behavioral Addictions, 6(4), 658-668. doi:10.1556/2006.6.2017.062

Hopper, J. W., Su, Z., Looby, A. R., Ryan, E. T., Penetar, D. M., Palmer, C. M., \& Lukas, S. E. (2006). Incidence and patterns of polydrug use and craving for ecstasy in regular ecstasy users: An ecological momentary assessment study. Drug and Alcohol Dependence, 85(3), 221-235. doi:10.1016/j.drugalcdep.2006. 04.012

Hussong, A. M., Hicks, R. E., Levy, S. A., \& Curran, P. J. (2001). Specifying the relations between affect and heavy alcohol use among young adults. Journal of Abnormal Psychology, 110(3), 449-461. doi:10.1037/0021-843X.110.3.449

Li, E., Browne, M., Langham, E., Thorne, H., \& Rockloff, M. (2018). Implicit associations between gambling and sport. Melbourne, Australia: Victorian Responsible Gambling Foundation.

Litt, M. D., Cooney, N. L., \& Morse, P. (2000). Reactivity to alcohol-related stimuli in the laboratory and in the field: 
Predictors of craving in treated alcoholics. Addiction, 95(6), 889-900. doi:10.1046/j.1360-0443.2000.9568896.x

Lopez-Gonzalez, H., Estévez, A., \& Griffiths, M. D. (2018a). Controlling the illusion of control: A grounded theory of sports betting advertising in the UK. International Gambling Studies, 18(1), 39-55. doi:10.1080/14459795.2017.1377747

Lopez-Gonzalez, H., Estévez, A., \& Griffiths, M. D. (2018b). Internet-based structural characteristics of sports betting and problem gambling severity: Is there a relationship? International Journal of Mental Health and Addiction. Advance online publication. 1-14. doi:10.1007/s11469-018-9876-x

Lopez-Gonzalez, H., \& Griffiths, M. D. (2017a). 'Cashing out' in sports betting: implications for problem gambling and regulation. Gaming Law Review, 21(4), 323-326. doi:10.1089/ $\operatorname{glr} 2.2017 .2144$

Lopez-Gonzalez, H., \& Griffiths, M. D. (2017b). Betting, Forex trading, and fantasy gaming sponsorships - A responsible marketing inquiry into the 'gamblification' of English football. International Journal of Mental Health and Addiction, 16(2), 404-419. doi:10.1007/s11469-017-9788-1

Lopez-Gonzalez, H., Guerrero-Solé, F., \& Griffiths, M. D. (2018). A content analysis of how 'normal' sports betting behaviour is represented in gambling advertising. Addiction Research \& Theory, 26(3), 238-247. doi:10.1080/16066359.2017.1353082

McMullan, J. L. (2011). Submission to the Joint Select Committee on Gambling Reform: Inquiry into interactive and online gambling and gambling advertising. Retrieved from http:// www.aph.gov.au/Parliamentary_Business/Committees/Senate_ Committees?url=gamblingreform_ctte/interactive_online_ gambling_advertising/submissions.htm

Milner, L., Hing, N., Vitartas, P., \& Lamont, M. (2013). An exploratory study of embedded gambling promotion in Australian football television broadcasts. Communication, Politics and Culture, 46, 177-198.
Newall, P. W. S. (2015). How bookies make your money. Judgment and Decision Making, 10(3), 225-231.

Queensland Government. (2018). Australian gambling statistics, 1991-92 to 2016-17 (34th ed.). Brisbane, Australia: Queensland Government Statistician's Office, Queensland Treasury.

R Core Team. (2013). R: A language and environment for statistical computing. Vienna, Austria: R Foundation for Statistical Computing. Retrieved from http://www.R-project.org/

Russell, A. M. T., Hing, N., Browne, M., \& Rawat, V. (2018). Are direct messages (texts and emails) from wagering operators associated with betting intention and behaviour? An ecological momentary assessment study. Journal of Behavioral Addictions, 7(4), 1079-1090. doi:10.1556/2006.7.2018.99

Shiffman, S., Gwaltney, C. J., Balabanis, M. H., Liu, K. S., Paty, J. A., Kassel, J. D., Hickcox, M., \& Gnys, M. (2002). Immediate antecedents of cigarette smoking: An analysis from ecological momentary assessment. Journal of Abnormal Psychology, 111(4), 531-545. doi:10.1037/0021-843X.111.4.531

Shiffman, S., Stone, A. A., \& Hufford, M. R. (2008). Ecological momentary assessment. Annual Review of Clinical Psychology, 4(1), 1-32. doi:10.1146/annurev.clinpsy.3.022806.091415

Sproston, K., Hanley, C., Brook, K., Hing, N., \& Gainsbury, S. (2015). Marketing of sports betting and racing. Melbourne, Australia: Gambling Research Australia.

Thomas, S. L., Lewis, S., McLeod, C., \& Haycock, J. (2012). 'They are working every angle'. A qualitative study of Australian adults' attitudes towards, and interactions with, gambling industry marketing strategies. International Gambling Studies, 12(1), 111-127. doi:10.1080/14459795.2011. 639381

Weibe, J. (2008). Internet gambling: Strategies to recruit and retain customers. Guelph, Canada: Ontario Problem Gambling Research Centre. 